\title{
Current Clinical and Technical Features of the Antegrade and Retrograde Approaches to Percutaneous Coronary Intervention for Chronic Total Occlusion
}

\author{
Toshiya Muramatsu
}

\begin{abstract}
Percutaneous coronary intervention for the treatment of chronic total occlusions (CTO) has experienced remarkable progress in recent years. Firstly, appropriate angiographic evaluation is essential for providing clear imaging of the coronary arteries and their branches. Observed in detail are the pattern, length, and direction of the CTO; the condition of the side branches; the pattern of vessels distal to the occluded segment; and the extent of calcification. Each of the collateral pathways is evaluated very carefully, and the course from the origin to the termination in the distal part of the occluded vessel is identified. Secondly, selecting adequate devices for treatment is very important. The antegrade approach, using conventional guidewire and microcatheters, is always the first choice. Progressively more rigid guidewires may be required, as well as special devices and techniques. The retrograde approach is indicated when the antegrade approach fails in cases where the entry point of the occlusion is not identified or in patients with extremely calcified lesions. The optimal collateral access for this technique is a wide and straight septal branch, but such an ideal vessel is rarely found. The retrograde approach is explained in detail, and suggestions are provided to overcome anticipated obstacles during the procedure. The experience gained at this service, along with the different strategies and the use of adequate devices, has led to a current procedure success rate of over $90 \%$ in cases of CTO.
\end{abstract}

DESCRIPTORS: Coronary occlusion. Angioplasty. Stents. Coronary angiography.
RESUMO

\section{Aspectos Clínicos e Técnicos Atuais das Abordagens Anterógrada e Retrógrada da Intervenção Coronária Percutânea para a Oclusão Crônica}

A intervenção coronária percutânea para o tratamento das oclusões crônicas tem feito progressos notáveis nos últimos anos. É essencial, em primeiro lugar, que seja feita avaliação angiográfica apropriada para se obter uma visão clara das artérias coronárias e seus ramos. Observe com detalhe o padrão, o comprimento e a direção da oclusão, a condição dos ramos laterais, o padrão de vasos distais ao segmento ocluso e a extensão da calcificação. Avalie cada uma das vias colaterais com muito cuidado e identifique o curso desde a origem até o término na parte distal do vaso ocluído. Em seguida, é fundamental a seleção de dispositivos adequados para que o sucesso do procedimento seja alcançado. A abordagem anterógrada, com a utilização de guias convencionais e microcateteres, é sempre a primeira escolha. Guias progressivamente mais rígidos podem ser necessários, assim como dispositivos e técnicas especiais. A abordagem retrógrada é indicada na falência da estratégia anterógrada, nos casos em que o ponto de entrada da oclusão não é identificado ou nos pacientes com lesões muito calcificadas. A via colateral ideal para ser utilizada nessa técnica é um ramo septal calibroso e reto, mas esse vaso ideal é raramente achado. A abordagem retrógrada é explicada em detalhes, assim como sugestões para contornar eventuais obstáculos durante o procedimento. A experiência acumulada em nosso serviço, com as diversas estratégias e o uso de dispositivos apropriados, fez com que alcançássemos na atualidade sucesso do procedimento em mais de $90 \%$ dos casos de oclusão crônica.

DESCRITORES: Oclusão coronária. Angioplastia. Stents. Angiografia coronária. 
$\mathbf{P}$ ercutaneous coronary intervention $(\mathrm{PCl})$ for the treatment of chronic total occlusion has experienced remarkable progress in recent years, and the Japanese interventional cardiologists have greatly contributed to its development. Technical innovations, including the retrograde approach, represent the major source of interest in this field, and the long-term prognosis has increasingly called attention to the treatment of this complex angiographic subgroup of patients.

\section{KEY POINTS OF PERCUTANEOUS CORONARY INTERVENTION FOR CHRONIC TOTAL OCCLUSION}

One of the most important and essential aspects of this type of procedure is the performance of appropriate coronary angiography. Images with at least three different projections are necessary to provide a clear view of the coronary tree. It is important to carefully observe the pattern of occlusion and its length and direction; the condition of the side branches; the pattern of the vessels distal to the occluded segment; and the extent of calcification. It is also highly important to evaluate each of the collaterals very carefully, and to identify the path from the origin to the distal end of the occluded vessel. Recently, the retrograde technique has been more frequently utilised; thus, the analysis of the collateral must be even more selective. This technique, which is performed through collateral circulation, may be used in several forms, and a septal branch is usually chosen. Caudal and cranial right projections, in addition to side projections, are necessary to visualise these septal branches. During pre-intervention angiography, it is essential to identify the alternative collateral branches, which is necessary to administer good quality contrast injections. At this institution, it is common to perform a coronary angiotomography before performing $\mathrm{PCl}$ for chronic total occlusion, as this method contributes to establishing the path and structure of the lesions.

The selection of the material to be used is another fundamental aspect for the success of the procedure. First, to obtain adequate support, it is necessary to use 7-F or greater catheters. For ideal support, the Amplatz left $(\mathrm{AL})$ catheters are used for interventions in the right coronary, and the extra back-up catheter is used in the left coronary. These catheters must be handled very carefully, as the deep coupling of their edges will easily injure the proximal portion of the coronary artery. At this institution, the catheters with side holes are frequently used, in order to avoid the pressure damping phenomenon during the procedure.

\section{RETROGRADE TECHNIQUE}

Usually, guides with soft-tipped catheters and microcatheters are used as a first option. A tapered guide with a 0.009-inch tip was recently released to the market. For cases in which a microchannel can be clearly identified, a tapered guide can be used as a first option.

When no guide type is able to penetrate the occlusion, the Conquest Pro $^{\mathrm{TM}}$ guide may be used (Asahi Intecc Co. Ltd. - Japan). If the lesion is extremely calcified, a guide with a harder tip, such as the $12 \mathrm{~g}$ or $20 \mathrm{~g}$ Conquest Pro $^{\mathrm{TM}}$, must be used. In case of occlusion of the coronary angle segment, the Miracle guide series is used (Asahi Intecc Co. Ltd. - Japan) when the Conquest series is not appropriate for tortuous occlusions. This institution has collected a multicentre record using the Conquest Pro $^{\mathrm{TM}}$ guides, which led to favourable results with an initial success rate of $90 \%$ (Figure 1 ). When treating an occlusion, the guide must be rotated using the right hand and actively moved backwards and forwards with the left hand. It is necessary to be extremely cautious at the entry point of the occlusion, as a quick introduction may lead to the penetration of a false lumen. After successfully entering the true lumen, the guide may be advanced until the end of the occlusion, which is detected by a peculiar sensation. At this moment, the guide should not be rotated aggressively, as excessive rotations may expand the false lumen. If the guide penetrates the false lumen, resistance may be noted at its tip. The guide must be frequently moved backwards to ensure that it is advancing through the true lumen and not expanding the false lumen. When a false lumen is excessively expanded, it becomes difficult to return to the true lumen. As this problem can be corrected if detected early, it is necessary to check whether the guide is in the true or false lumen as soon as possible. In general, the guide penetrates the false lumen at the occlusion entrance. When it is necessary to enter the true lumen, the guide must be moved backwards, and the correct entry point at the beginning of the occlusion must be found. Otherwise, either the parallel guide technique or the intracoronary ultrasound-guided approach (IVUS) are appropriate to enter the true lumen. Nevertheless, the most desirable approach is to enter the lumen from the beginning, since managing the guide to re-enter the false lumen

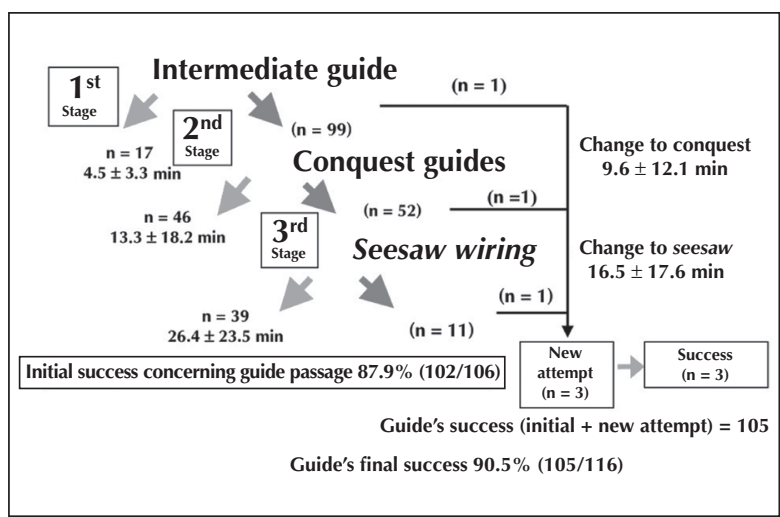

Figure 1 - CONQUEST study outcomes 
requires considerable ability. It is important to check the various projections of the lesion, because it is likely that all the attention has been focused exclusively on the occlusion. The biplanar angiography is ideal for this procedure; however, when only the uniplanar angiography is available, it is important to check whether the guide is located in the true lumen in at least two projections. Advancing the guide into a false lumen should be avoided, as it may lead to coronary perforation.

Even after the guide has crossed the lesion, it is common to experience difficulty advancing the balloon through the occlusion. A low-profile balloon catheter specifically designed to treat occlusions was recently developed and released in Japan. If the special balloon catheter does not cross the lesion, it is necessary to use the anchorage technique or the Tornus catheter (Asahi Intecc Co. Ltd. - Japan). When more support is needed, the mother-daughter technique may be used with the aid of catheters of different diameters (Rebirth aspiration catheter or Dio catheter). In the case of an extremely calcified lesion, using a rotablator device may be helpful.

\section{Late follow-up of patients}

In total, 606 patients with 1,145 occlusions were treated at institution between January of 1996 and December of 2003. Immediate success and a sixmonth angiographic patency of the vessel, which was confirmed through angiography, were determined in 436 patients who were part of the patent group. The other 170 patients, for whom the initial procedure did not succeed or who did not have the vessel occlusion confirmed through angiography, were assigned to the occlusion group. Chronic total occlusion is defined as an occlusion that has persisted for one or more months with a Thrombolysis in Myocardial Infarction (TIMI) flow equal to 0 or 1 . During the evolution of the study, the free-event survival rate was analysed and calculated on April of 2006, with an average follow-up time of $660 \pm 602$ days.

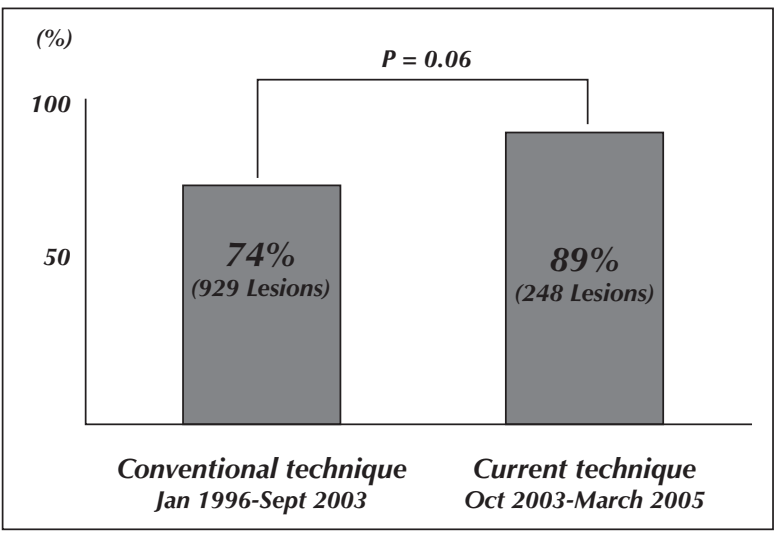

Figure 2 - Success rate of percutaneous coronary intervention for chronic total occlusion before and after the availability of the Conquest ${ }^{\mathrm{TM}}$ guides.
The initial success rate, which was $74 \%$ before 2003, when the Conquest Pro $^{\mathrm{TM}}$ guide series was not yet available, increased significantly to $89 \%$ afterwards (Figure 2). The survival rate was significantly higher in the patent group when compared with the occlusion group (92\% vs. 64\%; $P<0.0001$ ) (Figure 3 ). The combined adverse cardiovascular event-free survival (death, acute myocardial infarct, and target-lesion revascularisation) presented similar results ( $83 \%$ vs. 52\%; $\mathrm{P}=0.0003)$. When survival was evaluated in patients with little or no viability in the occlusion zone, it was also found to be higher in the patent group compared with the occlusion group (88\% vs. 55\%; P $<0.001)$. The outcomes were also evaluated in patients with other occluded arteries in addition to the treated artery. The event rates were significantly worse in patients with additional occluded vessels than in patients without other impaired arteries $(90 \%$ vs. $42 \% ; P=0.0003)$. The evolution was significantly better in the subgroup of patients with a left ventricular ejection fraction $>40 \%$ than in those with a left ventricular ejection fraction $\leq 40 \%(90 \%$ vs. $68 \%$; $P=0.002$ ). It was also significantly better in patients whose ventricular function improved after $\mathrm{PCl}$ was performed (94\% vs. $62 \% ; \mathrm{P}<0.0001)$. The independent predictors of cardiac death, which were identified at the multivariate analysis, were as follows: occlusion of the treated vessels, occlusion of another vessel, low left ventricular ejection fraction, left ventricular ejection fraction without improvement after $\mathrm{PCl}$, and advanced age (Table 1). The most frequent cause of death was myocardial infarction $(43 \%)$ due to the occlusion of another artery (54\%), followed by congestive heart failure (30\%) (Table 2).

\section{RETROGRADE TECHNIQUE}

The retrograde technique is utilised when the antegrade technique fails in cases where the entry point of the occlusion is not identified, or in patients with extremely calcified lesions.

\section{Guidewire passage by retrograde path (Figure 4)}

Firstly, it is necessary to identify whether there are appropriate collaterals for the retrograde approach. It is vital to obtain at least two projections that clearly highlight the collaterals. The ideal scenario, which is rarely encountered, is characterised by a large calibre and a straight septal branch. Even when the trajectory appears appropriate, sometimes this collateral presents an unexpected and tortuous curve, which obstructs the guide passage. A guide can pass through a relatively thin channel provided that the channel is straight. Epicardial collaterals have a larger calibre but are more sinuous.

The procedure for approaching the collateral consists of inserting a short guiding catheter and then using a smooth tip guide and a microcatheter to navigate the 


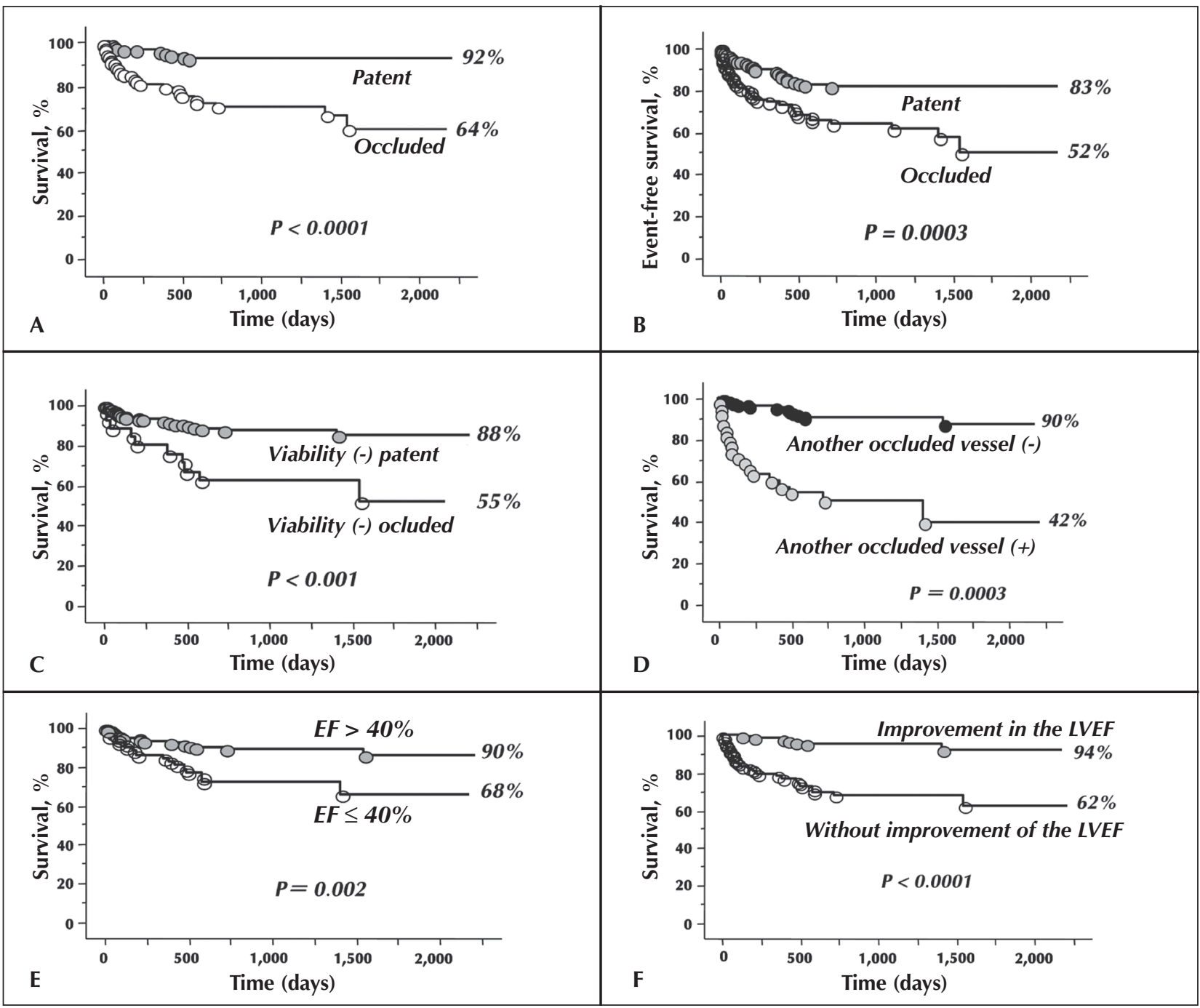

Figure 3 - In A, survival curve. In B, event-free survival curve for major adverse cardiovascular events. In C, survival curve according to the patency of the vessel in patients without myocardial viability. In D, survival curve related to another occluded vessel besides that being treated. In $\mathrm{E}$, survival curve related to the left ventricular ejection fraction $>40 \%$ or $\leq 40 \%$. In $\mathrm{F}$, the survival curve according to the response of the left ventricular ejection fraction.

vessel. A 7-F or greater guiding catheter is recommended to give a better support to the system. Currently, the FineCross ${ }^{\mathrm{TM}}$ microcatheter (Terumo Co. - Japan) is the most flexible and appropriate device for this procedure, although the channel dilator microcatheter has become increasingly popular since its release in Japan. Contrast injections are advisable to guarantee that the collateral artery is completely developed, providing an appropriate pathway for the contralateral vessel. First, a Fielder FC (Asahi Intecc Co. Ltd. - Japan) was used as a channel selector guide. Typically, a common guide with a smooth tip is used to guide the microcatheter in the chosen collateral. Then, it is replaced by a Fielder FC whose tip has only a small moulded curve to manage the collateral branch. The collaterals come from the main vessel in great angles and require tips with substantial curves. The Fielder FC guide is usually the first choice to navigate the collateral arteries. For narrower collaterals, the Fielder Extreme may be used; however, its edge is so thin (0.009 inches) and flexible that its introduction may be difficult, increasing the risk of damaging the vessel. Guide manipulation during this procedure is substantially different from that of the methods using the antegrade approach. The guide must be advanced slowly with subtle rotations in the collateral, and it is desirable that no resistance is encountered. Small sinuosities of the collateral cannot be identified when the images are only obtained in a projection. It is necessary to use various combined projections to obtain an adequate visualisation and perform correct 
TABLE 1

Predictor of Late Cardiac Death

\begin{tabular}{lcccc}
\hline Risk Factor & Risk Rate & $\mathbf{9 5 \%} \mathbf{~ C ~}$ & $\begin{array}{c}\text { Univariate Analysis } \\
\mathbf{P}\end{array}$ & $\begin{array}{c}\text { Multivariate Analysis } \\
\mathbf{P}\end{array}$ \\
\hline Occlusion of the target vessel & 0.15 & $0.09-0.26$ & $<0.0001$ & 0.008 \\
Occlusion of another vessel & 0.09 & $0.06-0.15$ & $<0.0001$ & $<0.0001$ \\
Diabetes mellitus & 0.43 & $0.26-0.72$ & 0.014 & 0.12 \\
EF $\leq 40 \%$ & 0.26 & $0.16-0.3$ & $<0.0001$ & 0.0005 \\
Viability (-) occluded & 0.3 & $0.1-0.6$ & 0.0007 & \\
Viability (+) occluded & 0.2 & $0.1-0.5$ & 0.0004 & \\
Without improvement of the EF & 10.9 & $5.69-20.9$ & $<0.0001$ & \\
Occluded RCA and LAD & 0.14 & $0.08-0.24$ & $<0.001$ & \\
Renal failure & 0.26 & $0.1-0.5$ & 0.0001 & \\
Grade 3 collateral & 1.59 & $1.19-3.22$ & 0.008 & \\
Proximal chronic total occlusion & 0.6 & $0.3-1.06$ & 0.08 & 0.08 \\
Unsuccessful & 3.59 & $2.18-5.9$ & $<0.0001$ & 0.0005 \\
$>75$ years & 0.32 & $0.2-0.53$ & $<0.0001$ & \\
\hline
\end{tabular}

RCA: right coronary artery; LAD: left anterior descending artery; EF: ejection fraction; Cl: confidence interval.

TABLE 2

Causes of Cardiac Death

\begin{tabular}{lc}
\hline & $\mathbf{n}=\mathbf{3 7}$ cases \\
\hline Occlusion of another artery & $54 \%(20 / 37)$ \\
MI & $43 \%(16 / 37)$ \\
Prior MI & $11 \%(4 / 37)$ \\
CHF & $30 \%(11 / 37)$ \\
VF & $8 \%(3 / 37)$ \\
Sudden death (non-AMI) & $8 \%(3 / 37)$ \\
\hline VF = ventricular fibrillation; CHF = congestive heart failure; \\
AMI = acute myocardial infarction; IM = myocardial infarction. \\
\hline
\end{tabular}

guide manipulation. When resistance is encountered, the guide must never be advanced based on only one projection, as uninformed guide manipulation may lead to collateral dissection or perforation.

\section{Scenarios after the guidewire passage}

1) When the guide crosses the occlusion retrogradely (Figure 5)

When it is possible to advance the guide until it reaches the contralateral guide catheter, which is desirable, and if the microcatheter can be pushed into the guiding catheter, the guide may be replaced by a 3-m guide, which will exit from a femoral introducer ('externalisation'); then, a balloon can be placed antegradely without any difficulty. The long RG3 guide (Asahi Intecc Co. Ltd. - Japan), which was specifically developed for this purpose, makes the procedure faster and easier.

When the microcatheter cannot cross the occlusion, the kissing-wire technique must be used for the antegrade guide. In this technique, the retrograde guide becomes a reference point, which greatly facilitates the manipulation of the antegrade guide.

Alternatively, the retrograde guide may be fastened with the aid of a $2.5-\mathrm{mm}$ balloon, which is inflated inside the contralateral guide catheter (anchoring technique). A $1.25-\mathrm{mm}$ balloon catheter $(150 \mathrm{~cm}$ in length) or a Corsair may be retrogradely introduced through the collateral and passed through the occlusion to dilate the lesion.

\section{2) When the guide fails in crossing the occlusion retrogradely}

In a patient with an extremely calcified occlusion, even when the guide navigates successfully through the collateral, it is possible that the guide does not cross the lesion. In this situation, a microcatheter may be inserted into the occlusion to provide more support to the Fielder guide. Usually, the guide penetrates the false lumen; however, it can be carefully advanced through the vessel. If it becomes difficult to advance the guide, another guide must be inserted via the antegrade approach using the retrograde guide as a frame of reference. When the two guides meet in the false 


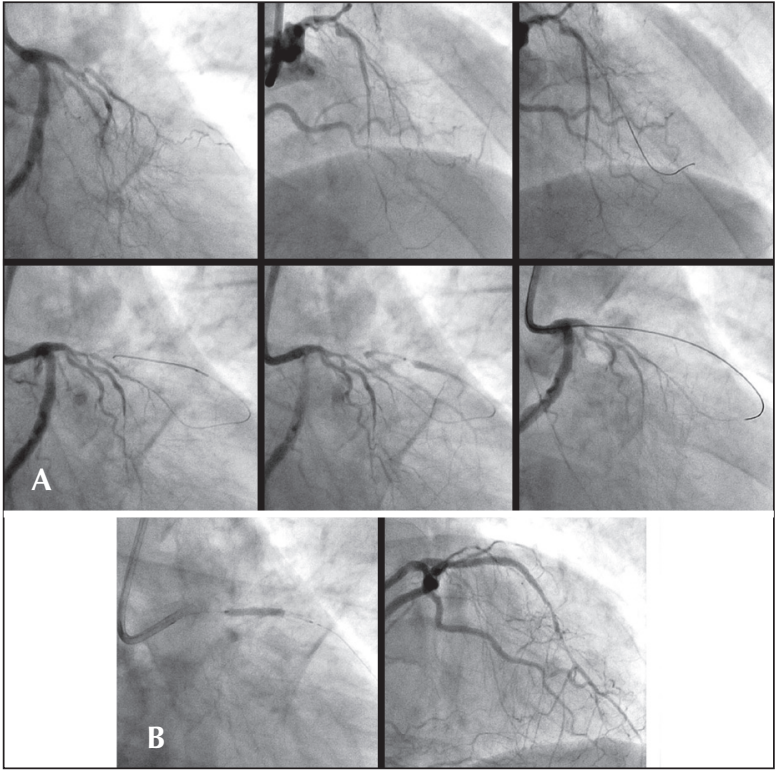

Figure 4 - Chronic total occlusion in the left anterior descending artery. In A, the guide is inserted via the ipsilateral septal channel and retrogradely positioned in the guide catheter. Then, it can be observed that the occlusion was dilated using a $2-\mathrm{mm}$ balloon through the retrograde path. In B, the Cypher stent is positioned and antegradely implanted in the lesion.

lumen, controlled antegrade retrograde tracking (CART) can be used. If the soft tip guide (Fielder XT or FC) of the retrograde pathway does not cross the lesion, the guide must be replaced by a more rigid guide, and the microcatheter must be introduced beforehand, up to the closest point of the occlusion. If this procedure is not possible, an over-the-wire (OTW) balloon catheter $(1.25 \mathrm{~mm})$ must be introduced to dilate the septal branch at a pressure of $3 \mathrm{~atm}$. After the OTW balloon catheter or the Corsair has been successfully introduced, the soft guide must be replaced by a more rigid one. To replace the Fielder guide, the 6-gauge Miracle guide is normally used, which can be advanced retrogradely through the occlusion. When an even more rigid guide is necessary, the 12-gauge Miracle can be used. The Conquest series guide can also be used in cases without tortuosity or angulation. Nevertheless, it is necessary to remember that the guide of the retrograde pathway is in the false lumen, and it is highly important to keep it inside the vessel. When the occlusion is extremely calcified, it will usually be difficult to penetrate the true lumen and, consequently, the first guide will be in the false lumen, making it necessary to use the kissing-wire or the CART technique.

\section{3) Corsair microcatheter (Figure 6)}

The Corsair was specifically developed for the retrograde approach, and although it was not available on the Japanese market until 2010, it is already considered to be a first-choice device for this technique. Compared

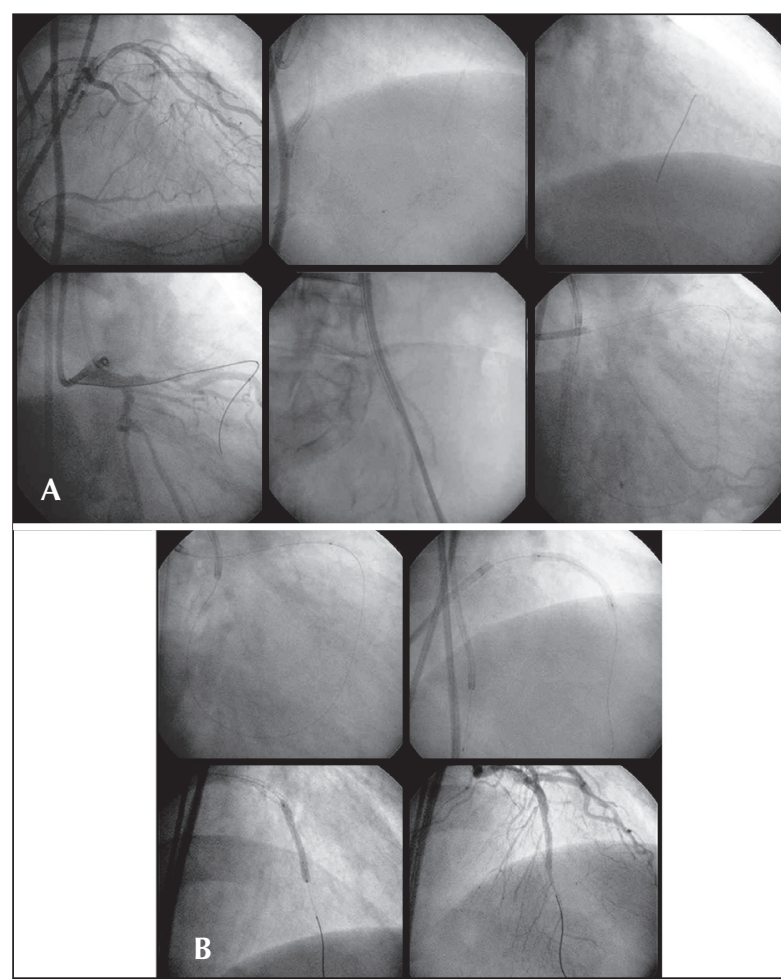

Figure 5 - Chronic total occlusion of the left anterior descending artery. In $\mathrm{A}$, the guide is inserted through the ipsilateral septal channel, and is positioned in the contralateral guide catheter. Then, the guide was replaced by a 3-m guide, which was removed through a collateral introducer using a snare guide to guarantee good support. In B, with an appropriate support, a $1.25-\mathrm{mm}$ balloon is passed contralaterally, followed by a stent implant.

with conventional microcatheters, it can advance more easily through the collaterals, which facilitates the following procedure. After insertion into the collateral, this device must be rotated with the right hand and advanced with the left hand, which makes it possible to introduce it without much resistance. As the Corsair has a tapered tip, it can cross the occlusion retrogradely and be pushed up to the contralateral catheter. Then, it can be replaced by a 3-m guide, and 'externalisation' can easily occur.

\section{4) Advantages of the reverse CART technique (Figure 7)}

As the use of the Corsair microcatheter became more common, the reverse CART technique became popular. This technique consists of antegradely - but not retrogradely, as in conventional techniques - positioning a balloon in the false lumen to expand it. Although this technique is necessary for the Corsair catheter, it also has other advantages. For example, the insertion of a balloon is easier with the retrograde technique than with the antegrade technique, and a larger balloon or even an IVUS catheter may be used. Nevertheless, it is 


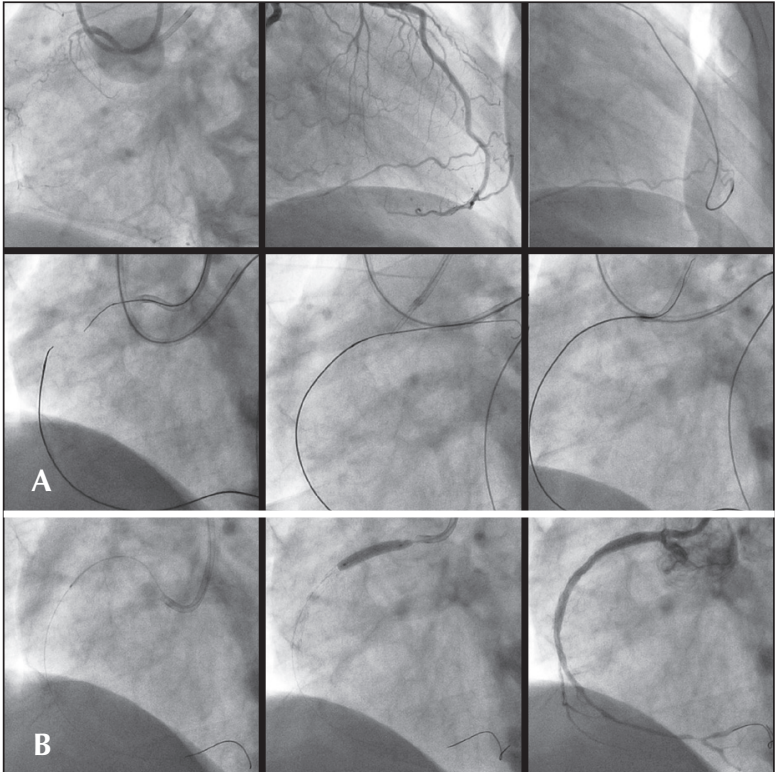

Figure 6 - Chronic total occlusion in the right coronary artery. In A, the Corsair microcatheter is inserted via the epicardial collateral and is advanced retrogradely up to the distal portion of the occlusion. A snare catheter positioned antegradely captures a 3-m guide, which is externalised in the contralateral guide catheter, guaranteeing good support. In B, a conventional guide was inserted antegradely with the aid of a microcatheter, and a Cypher stent was positioned and released into the lesion.
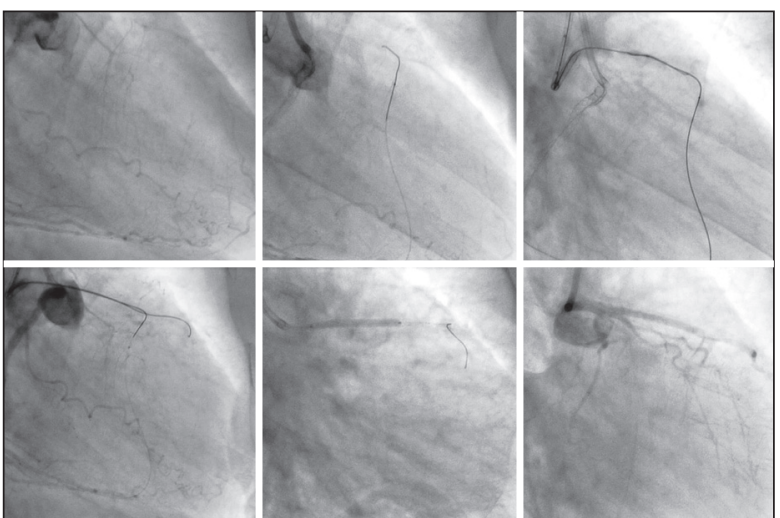

Figure 7 - Chronic total occlusion of the left anterior descending artery. The guide was inserted via retrograde passage through the septal collateral; another guide inserted antegradely, until the two guides met in the false lumen, which was expanded with a 2-mm balloon. A new guide can successfully cross the occlusion through the reverse CART technique.

necessary that both the antegrade and retrograde guides are at the false lumen. It is important to highlight that contrast injections must be avoided, as they may induce spiral dissections into the false lumen.

\section{5) Complications associated with the retrograde approach (Figure 8)}

The main complications associated with this technique consist of dissection and perforation of the

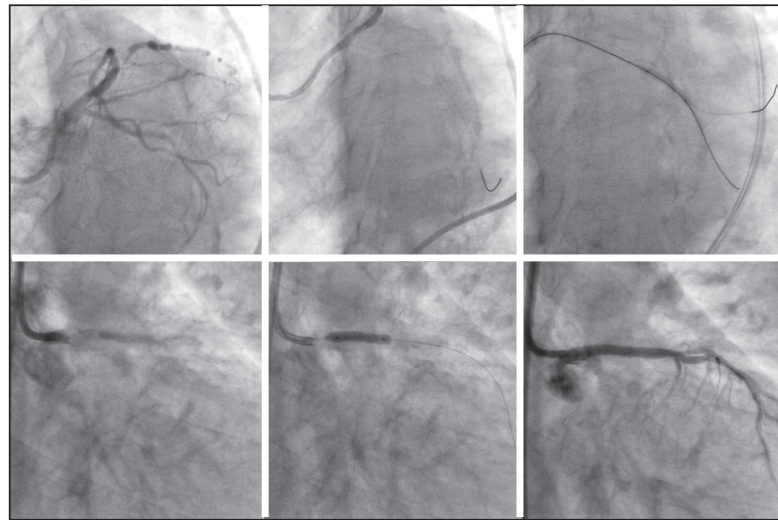

Figure 8 - Chronic total occlusion in the circumflex artery. The guide was inserted via the ipsilateral collateral passage. It was passed through the occlusion using the kissing-wire technique. However, during the procedure, left main coronary artery thrombosis was identified, and stent implantation was necessary.

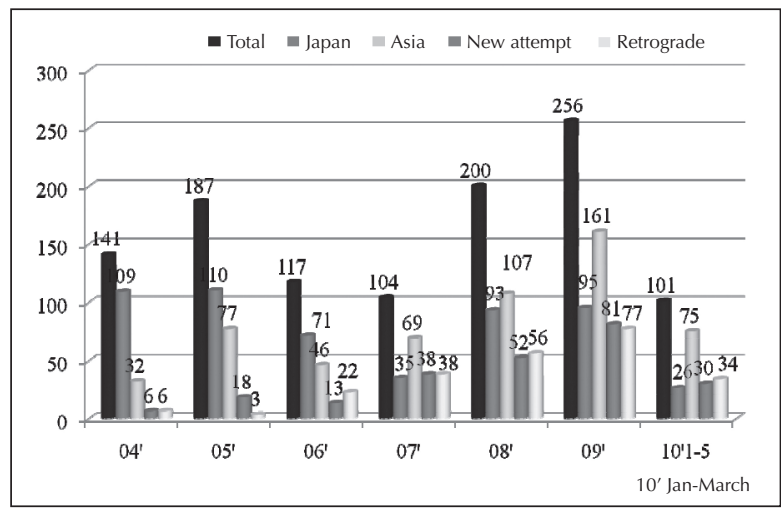

Figure 9 - Number of chronic total occlusions between 2004 and 2010

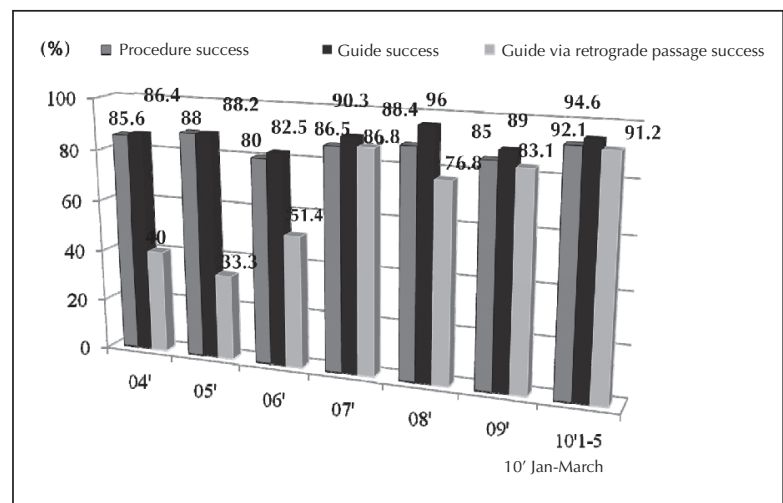

Figure $\mathbf{1 0}$ - Success rates of the procedure and of the guide crossing the occlusion.

collateral branch. Fortunately, with this approach, severe complications are rare when the septal branch is used. Even when perforation occurs, in most cases, blood flows to the ventricle, causing minor problems; therefore, it is not necessary to perform intervention in addition to monitoring during hospital follow-up. Occasionally, the blood may flow into the myocardium 
TABLE 3

Retrograde Approach

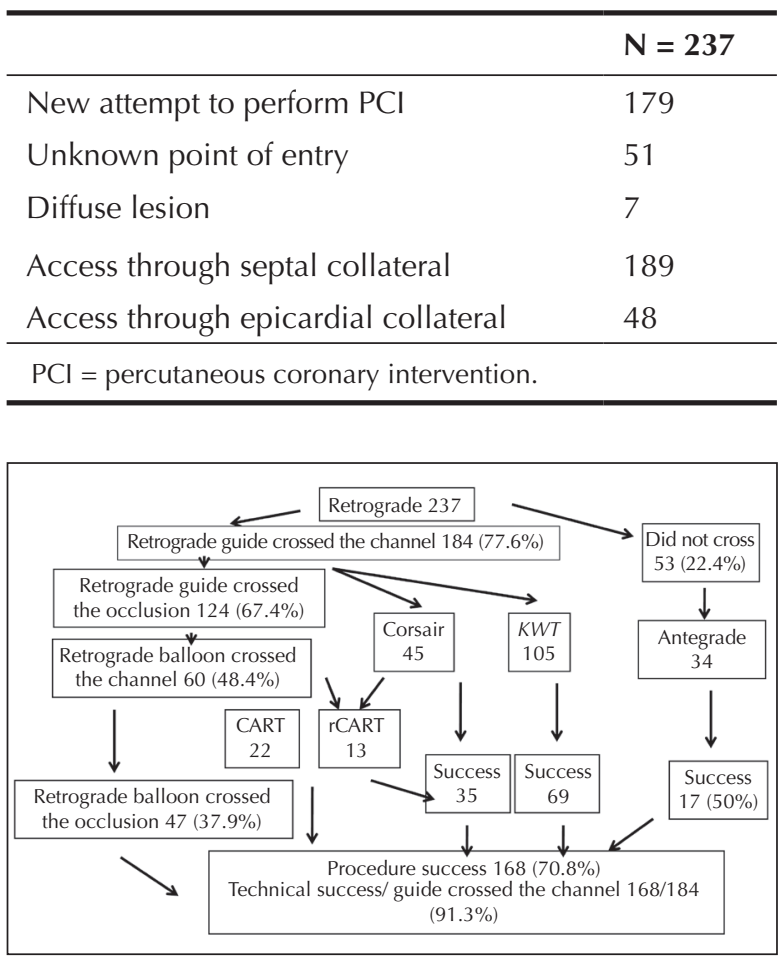

Figure 11 - Retrograde technique flowchart. KWT = kissing-wire technique; rCART $=$ reverse CART.

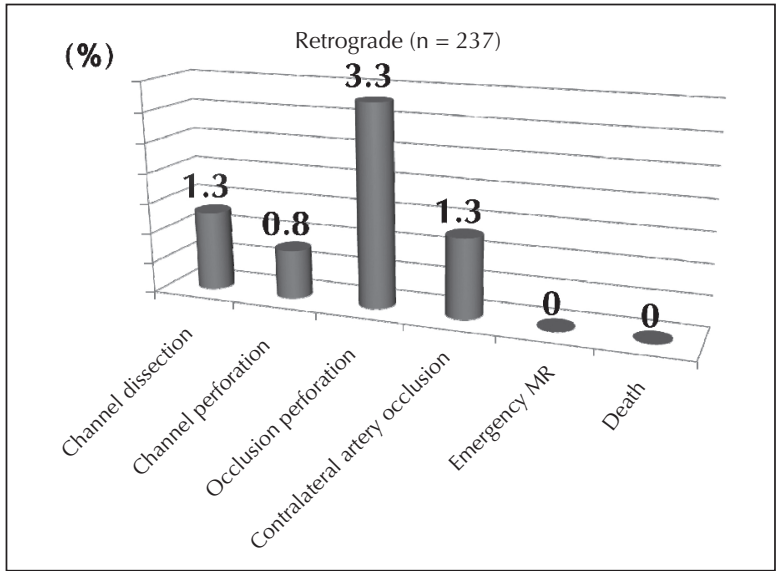

Figure 12 - Complications of the retrograde approach.

and accumulate as a fast-growing haematoma requiring haemostasis. Dissections and perforations are usually caused by the guide; however, they may also be caused by microcatheters. In the case of a perforation of the epicardial collateral, it is imperative to perform a pericardial drainage, as such perforation may result in tamponade. Other severe complications include acute obstruction by a thrombus or artery dissection resulting in collateral circulation. These events may be critical because the target vessel is already occluded. In two

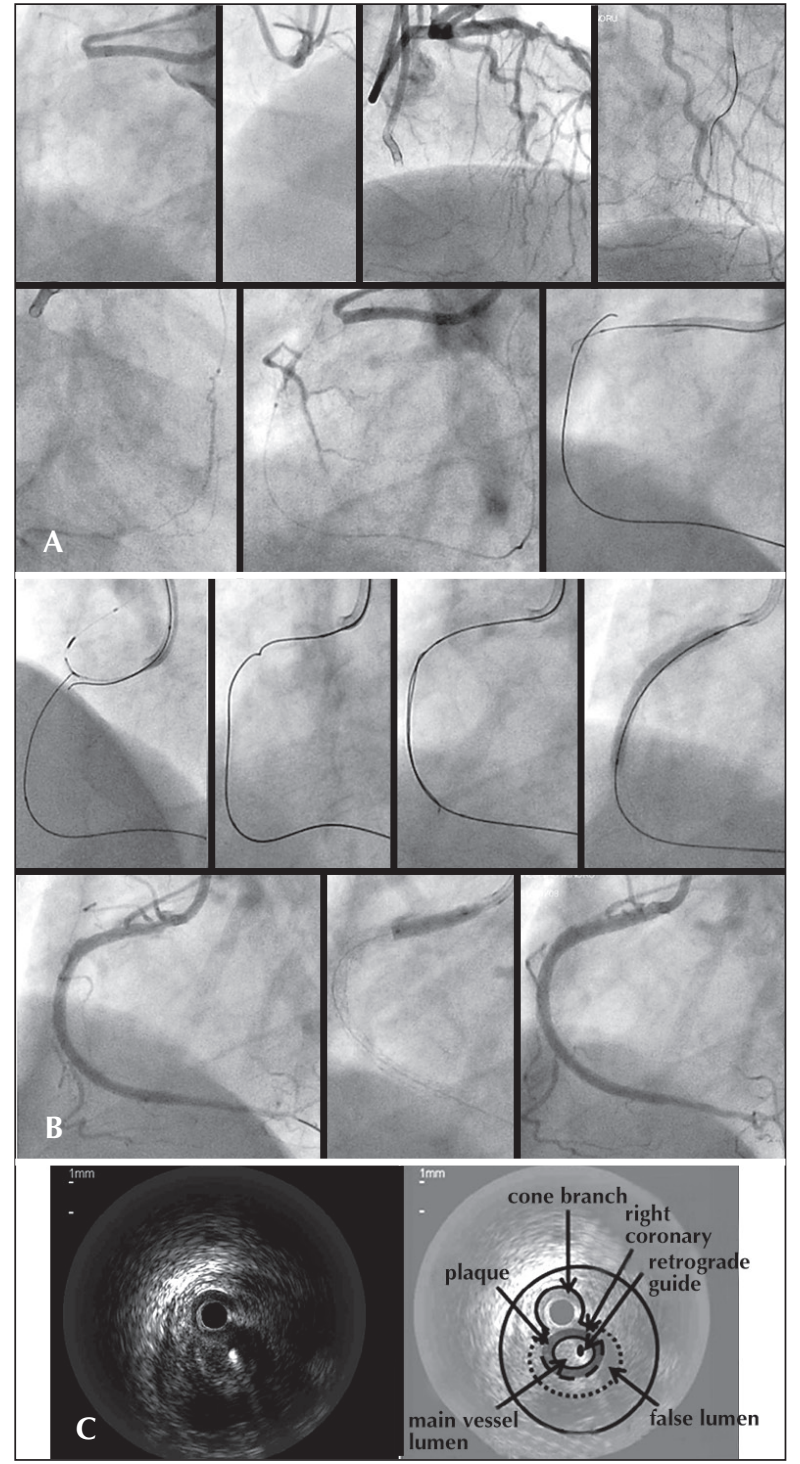

Figure 13 - In A, the following are shown in sequence: an occluded right coronary artery where the entry point is not evident; the left anterior descending artery emitting a 3-degree collateral through a septal channel; injection via microcatheter, which clearly indicates the collateral angulation; the microcatheter successfully advancing through the collateral by using a Fielder FC guide until reaching the distal portion of the occlusion; and antegrade and retrograde guides overlapping the false lumen. In B, an intracoronary ultrasound catheter antegradely positioned in the cone branch to identify the entry point of occlusion; the retrograde guide redirected to a position determined by the intracoronary ultrasound catheter; antegrade and retrograde guides within the true lumen; the retrograde guide penetrating the true lumen using the kissing-wire technique; $3.5 \times 33 \mathrm{~mm}$ and $3.5 \times 18 \mathrm{~mm}$ Cypher stents implanted proximally; a final angiographic control showing good calibre and antegrade flow. In C, intracoronary ultrasound image showing a retrograde guide positioned in the true lumen of the occlusion.

cases of obstruction of the collateral source vessel, a thrombus appeared due to deep coupling of the guide catheter edge in the artery in one case, and a thrombus occurred because the procedure was performed 


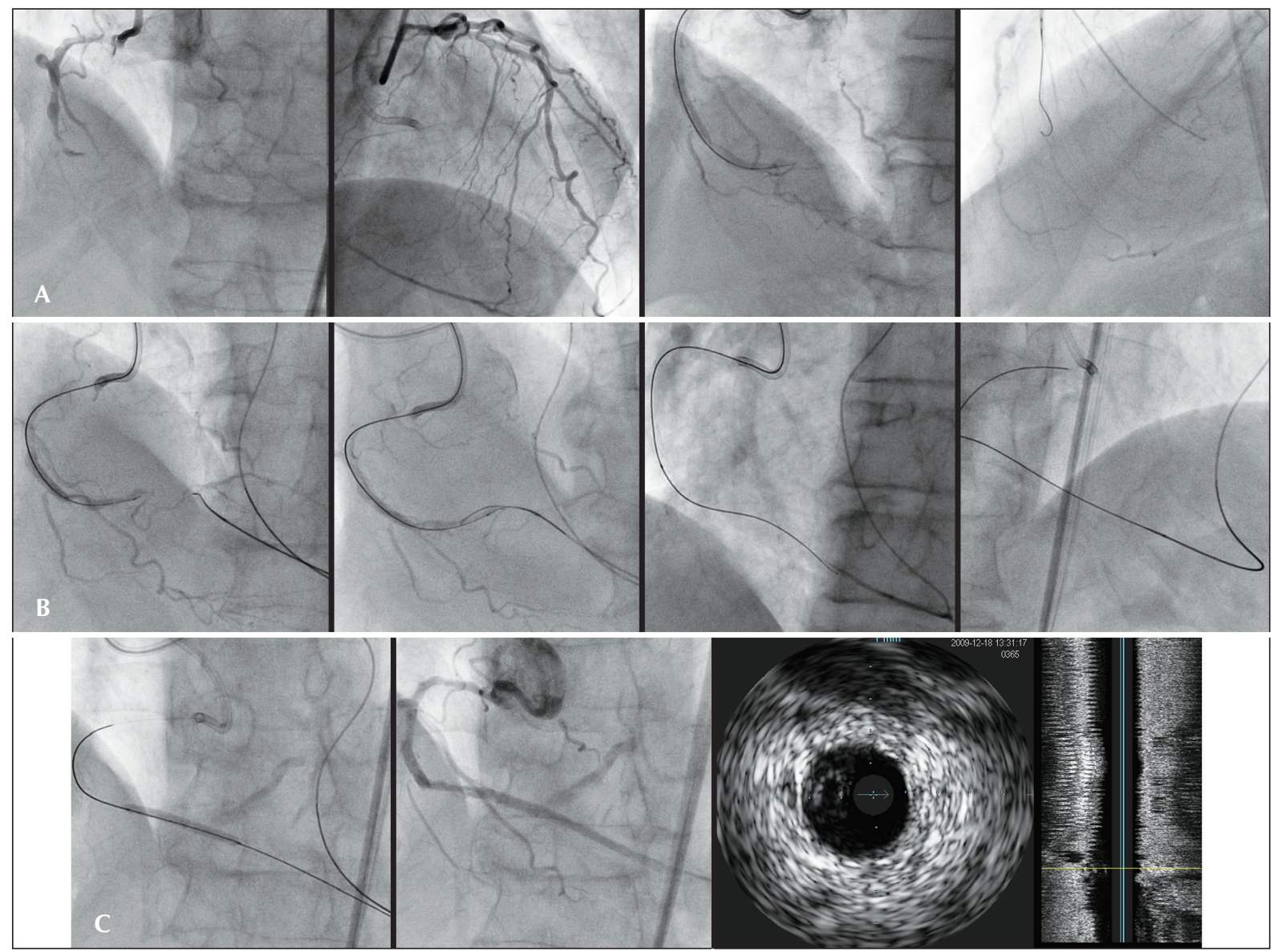

Figure 14 - In A, the following are shown in sequence: right coronary with a $90 \%$ lesion in the medium tertium, followed by occlusion in the distal tertium; left anterior descending artery emitting a 3-degree collateral through septal branches; unsuccessful passage of the antegrade guide; and a septal collateral showing great curvature, although the guide was navigated successfully. In B, the following can be observed: reverse CART technique failure in which it was not possible to advance the guide toward the true lumen through the false lumen; antegrade guide advancing inside the Corsair microcatheter, which is positioned via a retrograde pathway; retreat of the Corsair microcatheter; and the Conquest Pro guide, located at the subintimal space of the collateral, advancing toward the interior of the Corsair. In C, $2.5 \times 23 \mathrm{~mm}$ and $2.5 \times 28 \mathrm{~mm}$ Cypher stent implants and intracoronary ultrasound image showing the true lumen close to the false lumen after the dilation of the occlusion with the balloon.

with two microcatheters inside a 7-F catheter in the other case. Fortunately, in both cases, it was possible to reverse the situation with stent implants; however, this type of situation definitely constitutes the greatest concern regarding the retrograde technique, as patients can develop cardiogenic shock. To avoid such situations, it is necessary to check the position of the guide catheter; furthermore, when two microcatheters are to be used, an 8-F guide catheter must be used. The activated clotting time must be checked and maintained at $>300$ seconds. Narrow and tortuous paths should be avoided, as the guide may become stuck throughout the pathway and become difficult to remove.

\section{Experience with the retrograde technique}

In the first report on the retrograde approach, the guide was inserted through a coronary artery bypass surgery; however, in most cases, the retrograde technique is currently performed through native vessels. Since 2004, when the present study was initiated, various attempts were made in order to improve the devices and techniques. Between January of 2004 and May of 2010, 1,005 patients with chronic total occlusions were treated, and the success rates, the techniques used and the clinical outcomes were investigated.

The number of patients with chronic total occlusion has grown gradually, reaching 200 to 250 patients per year. It is noteworthy that the number of foreign patients has exceeded the number of Japanese patients. The number of new attempts of $\mathrm{PCl}$ has also increased, and now represents $25 \%$ to $30 \%$ of all patients with occlusion, which has led to a $30 \%$ increase in the utilisation of the retrograde approach (Figure 9). The success rate of the procedure and the guide passage was $85 \%$ to $90 \%$. In 2010 , the success rate related to the procedure, the guide passage, and the guide 
passage by the retrograde pathway was greater than $90 \%$ (Figure 10). New attempts of $\mathrm{PCl}$ were responsible for the majority of the procedures performed via the retrograde approach (179 patients), and a septal branch was used as the access point in 189 patients (Table 3). The outcomes related to the retrograde approach were thoroughly investigated in 237 patients, and the success rates of the guide passage and the occlusion crossing were $77.6 \%$ and $67.4 \%$, respectively. The antegrade approach was used in 34 out of 53 patients for whom the retrograde guide insertion failed. Only $50 \%$ of the cases were successful. After retrogradely passing the guide through the occlusion, balloons could be successfully introduced through the collateral artery in $48.4 \%$ of the cases. The retrograde technique was replaced by the kissing wire technique in 105 patients, and the antegrade wire successfully crossed the occlusion in 69 patients. Balloons associated with the CART techniques and the reverse CART techniques retrogradely crossed the lesions of 47 patients. The former technique was used in 22 patients, and the latter was used in 13 patients. Crossing the occlusion with the Corsair catheter was successful in 35 out of 45 patients for whom this device was used. The final success rate of the procedure was $70.8 \%$, with a significant increase to $91.3 \%$ when it was possible to navigate the guide through the collateral (Figure 11). The complications related to the retrograde approach included collateral dissection $(1.3 \%)$, collateral perforation $(0.8 \%)$, occlusion perforation $(3.3 \%)$, and occlusion of the artery that emits the collateral. None of the patients had to undergo myocardial revascularisation surgery, and no cardiac deaths were registered (Figure 12).

\section{Interesting cases}

After inserting the guide through the retrograde pathway, it is usually difficult to identify the re-entry point using angiography. In these cases, the IVUS helps to advance the guide. For example, in December of 2009, one patient underwent $\mathrm{PCl}$ via the retrograde route to treat the occlusion of the right coronary artery. Initially, the retrograde technique was used by inserting a Fielder guide through a septal branch of a left anterior descending artery. Then, since the re-entry point could not be identified in the occlusion, an ICUS catheter was introduced antegradely in the cone branch to indicate the entry point of the occlusion. Using an ICUS catheter as a reference point, the retrograde guide was successfully advanced through the true lumen of the right coronary artery (Figure 13). The intracoronary "rendez-vous" technique can be useful when it is difficult to identify the re-entry of the guide from the subintimal space to the true lumen using the reverse CART technique. A 77-year-old patient underwent $\mathrm{PCI}$ to treat the occlusion of the right coronary artery via a retrograde route through the septal branch. A FC Fielder guide followed by a Corsair microcatheter progressed through the microchannel up to the distal point of occlusion of the right coronary. Although two techniques (kissing-wire and reverse CART) were used, it was not possible to lead the guide from the false to the true lumen. Subsequently, a Conquest Pro ${ }^{\text {TM }}$ guide was selected and an attempt was made to advance it antegradely through the occlusion until the Corsair was penetrated. The Corsair was located at the subintimal space. After various attempts, the guide finally progressed to the Corsair (Figure 14).

\section{CONCLUSIONS}

Percutaneous treatment of occlusions in Japan is known as an advanced medical technique worldwide, thanks to the strong efforts of pioneers in this field. This treatment has been demonstrated to improve the long-term prognosis. In the future, interventional cardiologists who are familiar with the new devices and knowledgeable about this technique will be leaders in the field.

$\mathrm{PCl}$ in chronic total occlusions is the greatest and final challenge to be tackled by interventionists, and those responsible for the procedures should attempt to achieve excellence in the treatment of cardiovascular diseases.

\section{CONFLICTS OF INTEREST}

The author declares no conflicts of interest. 